\title{
Non-Hodgkin's lymphoma of the bronchial mucosa presenting with reversible airflow obstruction
}

\author{
GE PACKE, CW EDWARDS, RM CAYTON \\ From the Departments of Respiratory Physiology and Histopathology, East Birmingham Hospital, \\ Birmingham
}

Virtually all primary non-Hodgkin's lymphomas of the lower respiratory tract affect the lung parenchyma and are associated with an abnormal chest radiograph.' We report a patient with non-Hodgkin's lymphoma of the mucosa of the major bronchi, who presented with reversible airflow obstruction. There was no other clinical or radiographic evidence of tumour and the disease responded rapidly and completely to radiotherapy.

\section{Case report}

A 43 year old woman, who smoked 15 cigarettes a day, gave a six month history of increasing breathlessness on exertion, wheeze, and an unproductive cough. Physical examination revealed no abnormality. The chest radiograph showed features consistent with emphysema. Spirometric measurements were: FEV 2.11 (77\% predicted), forced vital capacity (FVC) 4.51 (125\%), and FEV $/ F V C$ ratio $47 \%$. The expiratory limb of a maximal flow-volume loop showed a concave upward pattern consistent with diffuse intrathoracic airflow obstruction, while the inspiratory limb had a normal configuration (fig 1); the peak expiratory flow (PEF) was $3151 \mathrm{~min}^{-1}$ (75\%) and the VC flow ratio ( $\dot{V}_{E m a x} / \dot{V}_{\text {I }} \max _{\text {s0 }}$ ) 0.35. The ratio of FEV (ml) to PEFR (1 $\left.\mathrm{min}^{-1}\right)$ was 6.7. Total lung capacity measured by helium dilution was $6.61(120 \%)$ and the transfer coefficient $0.80 \mathrm{mmol} \mathrm{min} \mathrm{m}^{-1} \mathrm{kPa}^{-1} \mathrm{l}^{-1}$ (45\%). Treatment with inhaled salbutamol and beclomethasone dipropionate was unhelpful but a trial of prednisolone (40 mg daily) improved her symptoms and lung function: FEV increased by $29 \%$ to 2.71 and FVC by $4 \%$ to 4.71 .

She remained well while taking inhaled salbutamol and beclomethasone dipropionate for several months but was later readmitted to hospital with increasing breathlessness. She had stridor, and auscultation of the chest showed widespread expiratory wheezes. The chest radiograph was unchanged. The FEV , was 1.31 and the FVC 4.6 1 .

A repeat flow-volume loop (fig 1) now showed the features of central intrathoracic airways obstruction with a considerable reduction in flow at high lung volumes (PEF) and reduced flows throughout expiration and inspiration, flow limitation being greater during expiration; the mid VC flow ratio was 0.23 and the $F E V_{1} /$ PEFR ratio was 14.4 .

Address for reprint requests: Dr GE Packe, Department of Respiratory Physiology, East Birmingham Hospital, Birmingham B9 5ST.

Accepted 13 April 1985
Rigid bronchoscopy showed that the mucosa of both main bronchi was thrown into deep folds causing narrowing of the lumina to one quarter of the normal diameter. These changes began at the carina and extended circumferentially down both main bronchi to the origins of the left and right upper lobe bronchi. Investigations with normal or negative results included a full blood count, erythrocyte sedimentation rate, blood biochemistry, and sputum cytology. The histological appearances were reported as those of anaplastic carcinoma and she received "palliative" radiotherapy of $3000 \mathrm{cGy}$ (rads) over the next two weeks. Her symptoms and lung function rapidly improved and she was discharged home. FEV, was 3.11 and FVC 4.2 1. The flow-volume loop after radiotherapy showed residual diffuse intrathoracic airflow obstruction (fig 1).

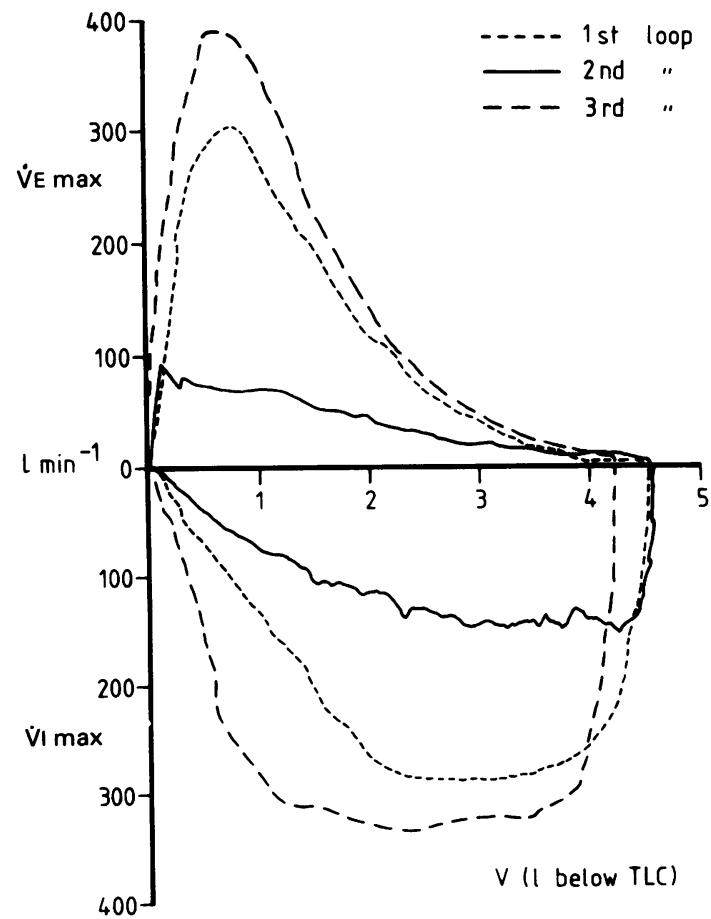

Fig 1 First and second flow-volume loops, obtained before radiotherapy, and third flow-volume loop, after radiotherapy. V-volume; $\dot{V}_{\text {Emax }}$ VImax - maximum expiratory and inspiratory flows. 


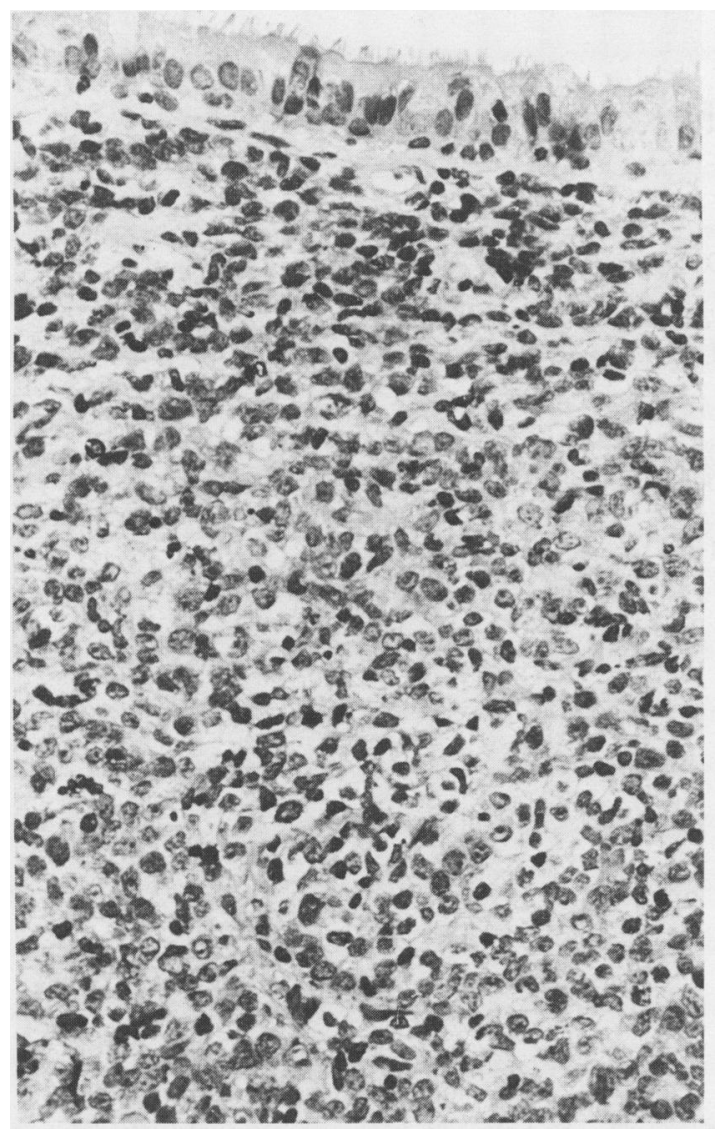

Fig 2 High grade lymphoma of the bronchial mucosa; the surface epithelium is intact. (Haematoxylin and eosin, $x$ 72.)

Two years later, because of her striking response to radiotherapy and her continued wellbeing, the original histological specimens were reviewed. The diagnosis was revised to poorly differentiated lymphoma, probably of centroblastic centrocytic type (fig 2). She was therefore reassessed for evidence of residual disease. Computed tomography of the chest showed changes in the upper lobes attributable to previous radiotherapy, but no other abnormality. Other investigations yielding normal results included computed tomography of the abdomen, full blood count, erythrocyte sedimentation rate, blood biochemistry, protein electrophoresis, peripheral lymphocyte marker tests, bone marrow aspiration, and trephine biopsy.

\section{Discussion}

Symptoms of localised central intrathoracic airways obstruction may mimic those of asthma. ${ }^{23}$ This was true of the present patient, where in addition considerable improve- ment followed a course of prednisolone. The smoking history, chest radiograph, and low transfer factor indicated that she also had emphysema. Prednisolone is used in most regimens for treating non-Hodgkin's lymphoma and it may have produced partial and temporary regression of the tumour with an improvement in airflow.

The value of serial measurements of simple lung function, including the flow-volume loop, is illustrated. Deteriorating symptoms, stridor, and a grossly abnormal flow-volume loop, quite different in configuration from the first record, clearly indicated that the patient's disease was not confined to the small airways. Direct bronchoscopic examination in such circumstances is the definitive investigation. ${ }^{4}$

Symptoms of airflow obstruction in lymphoma are usually caused by extrinsic compression of the central airways by enlarged mediastinal lymph nodes. Postmortem studies have shown that, less commonly, lymphoma can produce airway narrowing by direct invasion of the bronchial wall. ${ }^{5}$ Rarely, endobronchial infiltration has been diagnosed ante mortem by cytological examination of the sputum cytol$0 \mathrm{gy}^{6-8}$ or by bronchial biopsy 10 in patients with widespread non-Hodgkin's lymphoma. We believe the present case to be unusual in that the lymphoma was confined to the major bronchi with no evidence of disease elsewhere. The tumour may have arisen from lymphoid tissue in the bronchial submucosa and have extended preferentially into the bronchial lumen rather than invading adjacent lung tissue.

We thank Mr FJ Collins for performing the bronchoscopy.

\section{References}

1 Koss MN, Hochholzer L, Nichols PW, Wehunt WD, Lazarus AA. Primary non-Hodgkin's lymphoma and pseudolymphoma of lung: a study of 161 patients. Hum Pathol 1983;14:1024-38.

2 Isaacs D, Smyth JT, Bradbeer TL, Pagliero KM. Intrathoracic tracheal tumour presenting as asthma. Br Med J 1977;ii: 1332.

3 McGregor CGA, Herrick MJ, Hardy I, Higgenbottam T. Variable intrathoracic airways obstruction masquerading as asthma. Br Med J 1983;287:1457-8.

4 Grant IWB. Localised airway obstruction. Br Med J 1977;i:1157-8.

5 Moolton SE. Hodgkin's disease of the lung. Am J Cancer 1934;21:253-94.

6 Dawe BJ, Woolner LB, Parkhill EM, McDonald JR. Cytological studies of sputum, secretions and serous fluids in malignant lymphoma. Am J Clin Pathol 1955;25:480-8.

7 Schumann GB, Di Fiore K, Johnston JL. Sputum cytodiagnosis of disseminated histiocytic lymphoma: a case report. Acta Cytol 1983;27:262-6.

8 Manoharan A, Ford J, Hill J, Painter D, Miller D. Sputum cytology in the diagnosis of pulmonary non-Hodgkin's lymphoma. Thorax 1984;39:392-3.

9 Samuels ML, Howe DC, Dodd GD, Fuller LM, Schullenberger CC, Leary WL. Endobronchial malignant lymphoma: report of five cases in adults. $A J R$ 1961;85:87-95.

10 Banks DE, Castellan RM, Hendrick DJ. Lymphocytic lymphoma recurring in multiple endobronchial sites. Thorax 1980;35: 796-7. 